Case Report

\title{
Tongue Necrosis as an Initial Manifestation of Giant Cell Arteritis: Case Report and Review of the Literature
}

\author{
Jose R. Zaragoza, Natalia Vernon, and Gisoo Ghaffari \\ Division of Allergy \& Immunology, Penn State Hershey Allergy, Asthma \& Immunology, 500 University Drive, UPC II, \\ Suite 1300, Hershey, PA 17033, USA \\ Correspondence should be addressed to Gisoo Ghaffari; gghaffari@hmc.psu.edu
}

Received 12 November 2014; Accepted 7 January 2015

Academic Editor: Suleyman Serdar Koca

Copyright (C) 2015 Jose R. Zaragoza et al. This is an open access article distributed under the Creative Commons Attribution License, which permits unrestricted use, distribution, and reproduction in any medium, provided the original work is properly cited.

\begin{abstract}
Giant cell arteritis (GCA) is a systemic vasculitis of medium and large arteries that mainly affects the external carotid artery. It is a diagnosis of the elderly that typically presents as low-grade fever, temporal tenderness, claudication of the jaw, and in some patients vision loss. In cases where GCA presents with atypical manifestations, the diagnosis may be more difficult, causing a delay in both diagnosis and treatment and ultimately leading to irreversible complications. In this paper, we present an atypical presentation of GCA with symptoms of neck swelling and lingual pain in an elderly female. These symptoms progressed to bilateral necrosis and eventual dislodgement of the tongue. Lingual necrosis is a severe potential complication in GCA. In patients presenting with lingual swelling, pain, and discoloration, GCA should be suspected and prompt therapy should be initiated to avoid irreversible complications.
\end{abstract}

\section{Introduction}

Giant cell arteritis is a chronic vasculitis of large and medium sized vessels that commonly affects those above the age of 50 years. It has an estimated incidence of 20 cases per 100,000 individuals and a prevalence of 1 in 500 individuals [1]. Scandinavian and North American females are most commonly affected. Clinical presentation is usually fever, claudication of the jaw, and temporal headache. Less common presenting symptoms include dysphagia, cough, hearing loss, and necrosis of the tongue [2].

The diagnosis of GCA is clinicopathological for which the American College of Rheumatology (ACR) has established classification criteria. To meet the diagnosis criteria, patients should present at least 3 out of 5 positive findings. The ACR diagnostic tool does not include any lingual symptomatology amongst its criteria $[3,4]$ (Table 1$)$.

Lingual necrosis is a known complication of GCA that commonly affects one side of the tongue [5-8]. In a few cases bilateral necrosis has been described and is considered extremely rare due to the rich lingual vascular supply $[2,5,9-$ 11]. This paper presents a case of lingual pain and bilateral tongue necrosis secondary to GCA along with a literature review of this rare complication.

\section{Case Report}

A 68-year-old female patient was initially evaluated by her primary care physician for a nonspecific moderate headache and swelling of the neck for four weeks. She was treated with a course of antibiotics and nonsteroidal anti-inflammatory medications for ten days. After completing this therapy, the patient presented to the Emergency Department for acute onset of severe pain and progressive swelling of the tongue that was compromising her speech and deglutition. She was admitted to the hospital and treated with empiric antibiotic therapy and intermittent doses of systemic glucocorticoids for suspected sialadenitis. Progressive swelling of the tongue compromised feeding so the patient was then transferred to a tertiary care institution for further treatment and consulted with the allergy service for evaluation of angioedema as possible culprit on swelling.

Patient denied symptoms of fever, malaise, or weight loss. She did not have vision loss, jaw claudication, or temporal 
TABLE 1: Three out of five criteria are required to make the diagnosis of GCA.

\begin{tabular}{l}
\hline American College of Rheumatology diagnostic criteria \\
\hline (1) Age older than 50 years at onset of disease. \\
(2) New onset of localized headache. \\
(3) Abnormal temporal artery with tenderness or decreased \\
pulse. \\
(4) Erythrocyte sedimentation rate higher than $50 \mathrm{~mm} / \mathrm{hr}$. \\
(5) A biopsy of the artery showing necrotizing arteritis with \\
predominant mononuclear cell infiltrate or granulomatous \\
process with multinucleated giant cells.
\end{tabular}

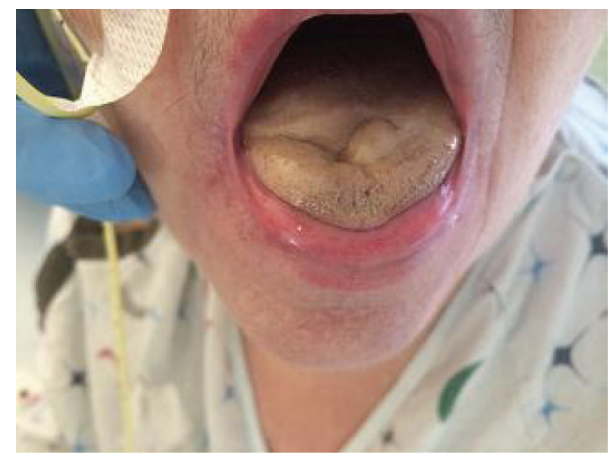

FIgURE 1: Discoloration and swelling of the anterior half of the tongue upon initial evaluation.

tenderness. Past medical history was negative for vasoconstrictor use, radiation therapy, cardiac arrest, or embolization. Vital signs were within normal limits with no evidence of cardiac or pulmonary abnormalities. Edema and discoloration involving the anterior half of the tongue with movement limitation were the main findings on physical examination. No temporal artery tenderness was noted (Figure 1).

Hematologic testing revealed mild leukocytosis, anemia and thrombocytosis (WBC: $13.8 \mathrm{ku} / \mathrm{L}, \mathrm{Hgb}: 12.4 \mathrm{~g} / \mathrm{dL}$, Hct: $37.8 \%$, Plt: $414 \mathrm{ku} / \mathrm{L}$ ), and mild neutrophilia on differential. The comprehensive metabolic panel was unremarkable.

Elevation in both C-reactive protein (CRP) and erythrocyte sedimentation (ESR) $(1.3 \mathrm{mg} / \mathrm{dL}$ and $55 \mathrm{~mm} / \mathrm{hr}$, resp.) was concordant with an acute inflammatory process. Antineutrophil cytoplasmic antibody was negative. Even though her presentation was atypical for angioedema, serum $\mathrm{C} 4$ levels and $\mathrm{C} 1$ esterase inhibitor and function were measured and found to be normal.

A tongue biopsy was performed and showed coagulative necrosis, and no malignant cells or amyloid deposits were identified. Imaging studies including a CT-angiography showed luminal irregularity of right cervical internal carotid artery described to have a "beaded appearance," suggesting arterial involvement and segmental luminal narrowing. A soft tissue defect of the anterior part of the tongue, consistent with avascular necrosis of the tongue, was noted.

GCA was confirmed with bilateral biopsies of the temporal arteries, which showed mixed inflammatory infiltrate composed of lymphocyte, histiocyte, and multinucleated
TABLE 2: Differential diagnosis in lingual necrosis.

Differential diagnosis in lingual necrosis

(1) Malignancy: (carcinoma, lymphoma, and sarcoma)

(2) Drugs: (vasopressin, chemotherapy, and ergotamine)

(3) Radiation therapy

(4) Cardiovascular: (hemorrhage, embolism, and cardiac arrest)

(5) Infection: (syphilis, tuberculosis)

(6) Systemic vasculitis: (giant cell arteritis, ANCA positive vasculitis)

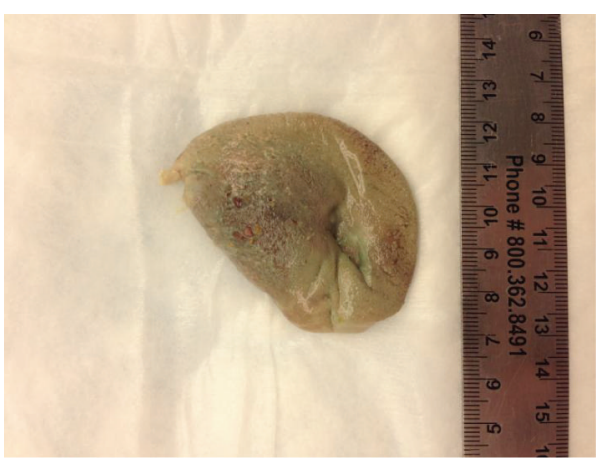

FIGURE 2: Necrotic appearance of the tongue posterior to dislodgement.

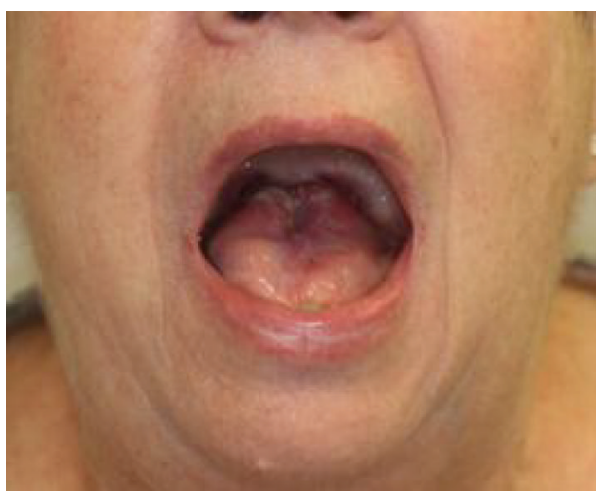

FIgURE 3: Appearance of the healed tongue.

giant cells with focal destruction of internal elastic lamina and marked intimal thickening significantly decreasing the lumen of both arteries, consistent with GCA vasculitis. Our patient met 3 of the 5 ACR criteria: age older than 50, elevated ESR, and histology consistent with GCA on both temporal arteries. Treatment with high dose corticosteroids was initiated at $1 \mathrm{mg} / \mathrm{kg}$. Unfortunately, the patient had extensive necrosis of the tongue that progressed to self-amputation of the anterior half of the tongue (Figures 2 and 3). No other organ system was involved. 


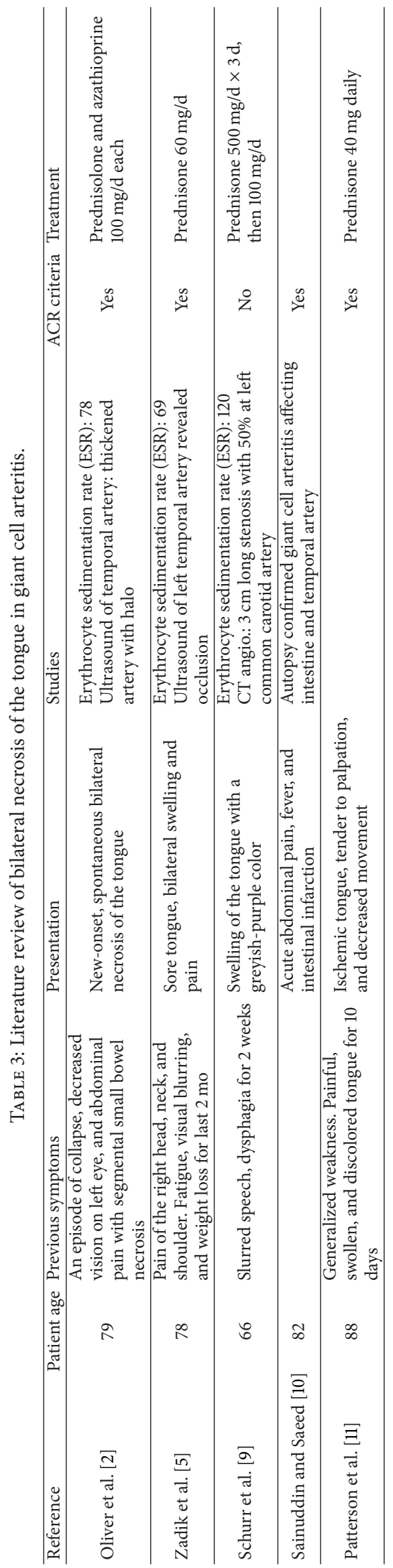




\section{Literature Review}

A PubMed based search was conducted combining the terms "giant cell arteritis and bilateral tongue necrosis," "lingual necrosis," and "ischemia." It included articles published in English and Spanish. We found that bilateral tongue necrosis in GCA has been previously reported in 5 patients. A history of atypical symptoms like dysphagia, lingual pain, and swelling was present in all the cases described. Typical symptoms were only seen in one patient described by Zadic et al., who presented with pain on right side of the head, visual blurring, and fatigue before evaluation (Table 3 ).

\section{Discussion}

In general, necrosis of the tongue is rare and may be caused by a wide array of different pathologies ranging from lingual malignancy, use of vasoconstrictor, and radiation therapy [12-17] (Table 2). This paper presents a case of bilateral tongue necrosis and eventual self-amputation of the tongue as a rare complication of GCA. Our case and the literature review of patients with this rare complication reveal that these patients often present with lingual pain and the absence of the typical symptoms of GCA ultimately delaying diagnosis and treatment. Patients with lingual pain or swelling nonresponsive to treatment for infection or angioedema should raise a high index of suspicion for a vasculitic process such as GCA, especially in patients above the age of 50. Physicians should be familiarized with this presentation since lingual swelling may prompt a consultation for evaluation for suspected angioedema, as was the case in our patient.

\section{Conflict of Interests}

The authors declare that there is no conflict of interests regarding the publication of this paper.

\section{Acknowledgments}

Thanks are due to Timothy Craig D.O. for his guidance and support and Thomas Samson MD for his contribution.

\section{References}

[1] J. M. Evans, W. M. O’Fallon, and G. G. Hunder, "Increased incidence of aortic aneurysm and dissection in giant cell (temporal) arteritis: a population-based study," Annals of Internal Medicine, vol. 122, no. 7, pp. 502-507, 1995.

[2] M. Oliver, B. Hugl, L. Posch et al., "Subtotal tongue necrosis in delayed diagnosed giant-cell arteritis: a case report," The American Journal of Otolaryngology-Head and Neck Medicine and Surgery, vol. 25, no. 6, pp. 438-441, 2004.

[3] G. G. Hunder, D. A. Bloch, B. A. Michel et al., "The American College of Rheumatology 1990 criteria for the classification of giant cell arteritis," Arthritis and Rheumatism, vol. 33, no. 8, pp. 1122-1128, 1990.

[4] B. Dasgupta, M. A. Cimmino, H. M. Kremers et al., "2012 Provisional classification criteria for polymyalgia rheumatic: a European League Against Rheumatism/American College of
Rheumatology collaborative initiative," Arthritis \& Rheumatism, vol. 64, no. 4, pp. 943-954, 2012.

[5] Y. Zadik, M. Findler, A. Maly, H. Rushinek, and R. Czerninski, "A 78-year-old woman with bilateral tongue necrosis," Oral Surgery, Oral Medicine, Oral Pathology, Oral Radiology and Endodontology, vol. 111, no. 1, pp. 15-19, 2011.

[6] M. Goicochea, J. Correale, L. Bonamico et al., "Tongue necrosis in temporal arteritis," Headache, vol. 47, no. 8, pp. 1213-1215, 2007.

[7] S. L. Pendás, J. C. de Vicente Rodríguez, M. G. García, L. M. J. Gutierrez, and J. S. L. Arranz, "Tongue necrosis as a complication of temporal arteritis," Oral Surgery, Oral Medicine, Oral Pathology, vol. 78, no. 4, pp. 448-451, 1994.

[8] O. Marcos, A. I. Cebrecos, A. Prieto, and M. Sancho De Salas, "Tongue necrosis in a patient with temporal arteritis," Journal of Oral and Maxillofacial Surgery, vol. 56, no. 10, pp. 1203-1206, 1998.

[9] C. Schurr, A. Berthele, M. Burghartz, and J. Kiefer, "Spontaneous bilateral necrosis of the tongue: a manifestation of giant cell arteritis?" European Archives of Oto-Rhino-Laryngology, vol. 265, no. 8, pp. 993-998, 2008.

[10] S. Sainuddin and N. R. Saeed, "Acute bilateral tongue necrosisa case report," British Journal of Oral and Maxillofacial Surgery, vol. 46, no. 8, pp. 671-672, 2008.

[11] A. Patterson, C. Scully, N. Barnard, M. J. Griffiths, J. W. Eveson, and M. Novelli, "Necrosis of the tongue in a patient with intestinal infarction," Oral Surgery Oral Medicine and Oral Pathology, vol. 74, no. 5, pp. 582-586, 1992.

[12] X. Leroy, A. Delobelle, J. L. Lefebvre, V. Cabaret, F. Bloget, and M. O. Vilain, "Epithelioid sarcoma of the tongue," Journal of Clinical Pathology, vol. 50, no. 10, pp. 869-870, 1997.

[13] A. Pollett, B. Perez-Ordonez, R. C. K. Jordan, and M. J. Davidson, "High-grade papillary cystadenocarcinoma of the tongue," Histopathology, vol. 31, no. 2, pp. 185-188, 1997.

[14] A. L. Weber, A. Rahemtullah, and J. A. Ferry, "Hodgkin and non-Hodgkin lymphoma of the head and neck: clinical, pathologic, and imaging evaluation," Neuroimaging Clinics of North America, vol. 13, no. 3, pp. 371-392, 2003.

[15] J. Bondeson, U. B. Ericsson, P. Falke et al., "Tongue necrosis in temporal arteritis provoked by ergotamine," Journal of Internal Medicine, vol. 232, no. 6, pp. 541-544, 1992.

[16] J. M. David, E. Paty, J. M. Bachaud, and J. R. Vignaud, "Lingual necrosis after radiotherapy: radiation arteritis?" Revue de Stomatologie et de Chirurgie Maxillo-Faciale, vol. 90, no. 5, pp. 334-336, 1989.

[17] P. Libersa, C. Loison-Blanchard, L. Nawrocki, and S. Duquesnoy, "Bilateral necrosis of the tongue consecutive to cardiac arrest," Journal of Oral and Maxillofacial Surgery, vol. 60, no. 3, pp. 322-323, 2002. 


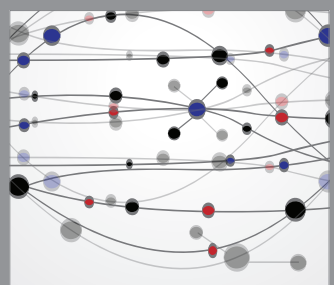

The Scientific World Journal
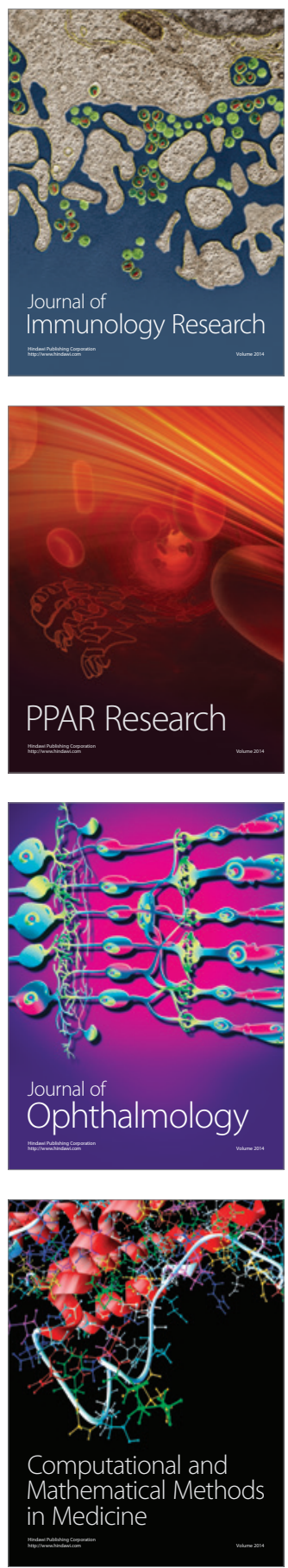

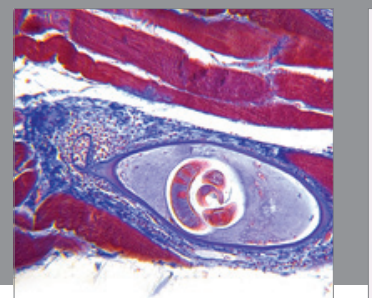

Gastroenterology

Research and Practice
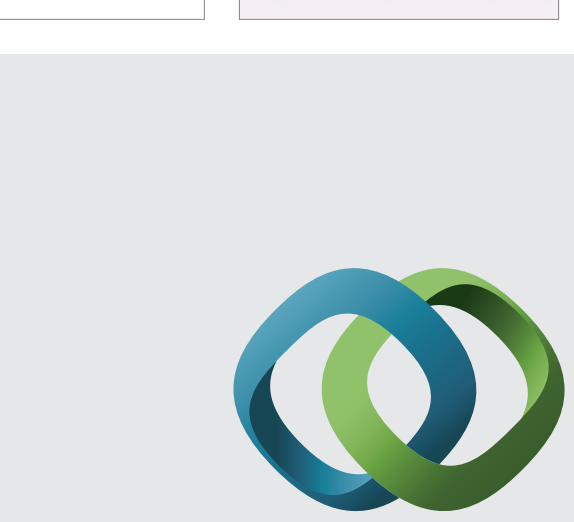

\section{Hindawi}

Submit your manuscripts at

http://www.hindawi.com
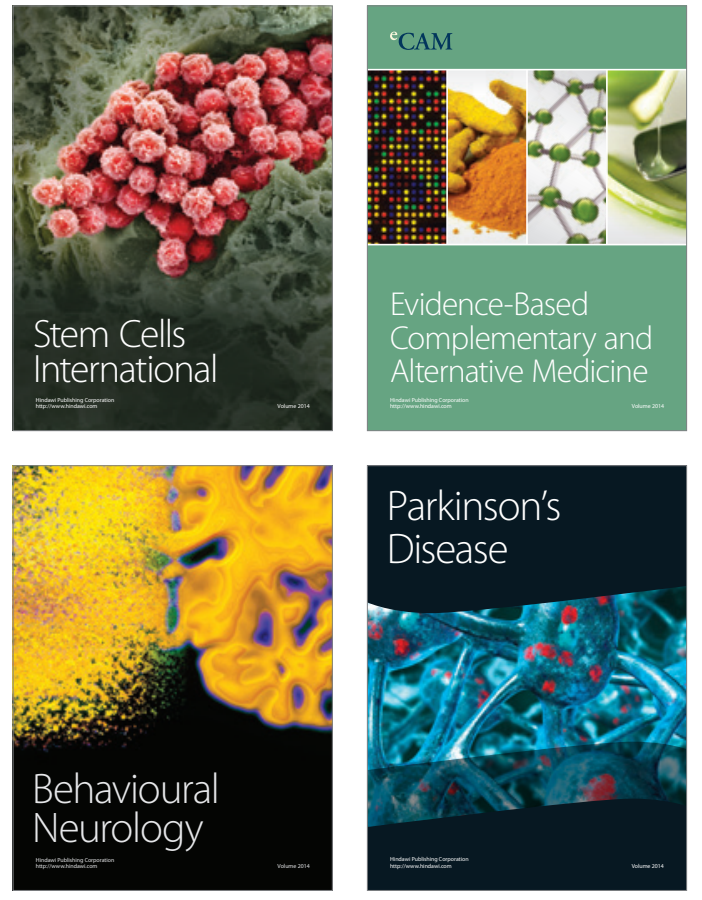
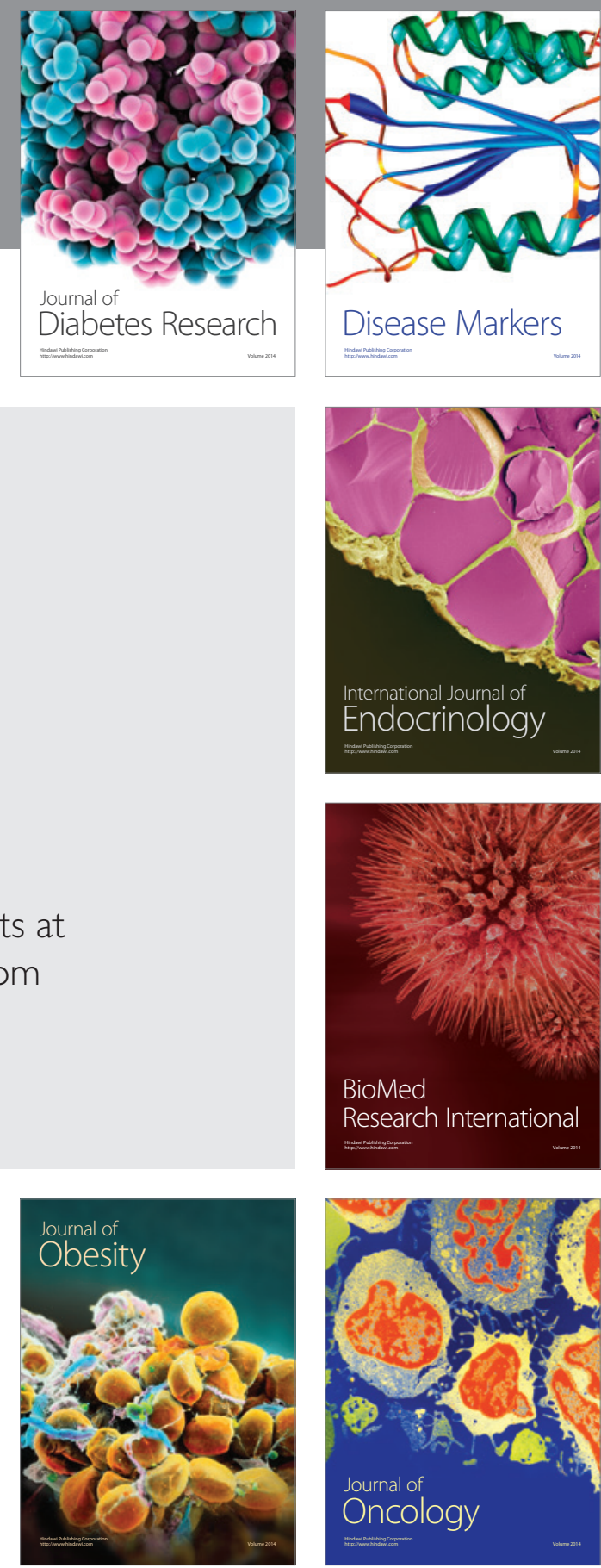

Disease Markers
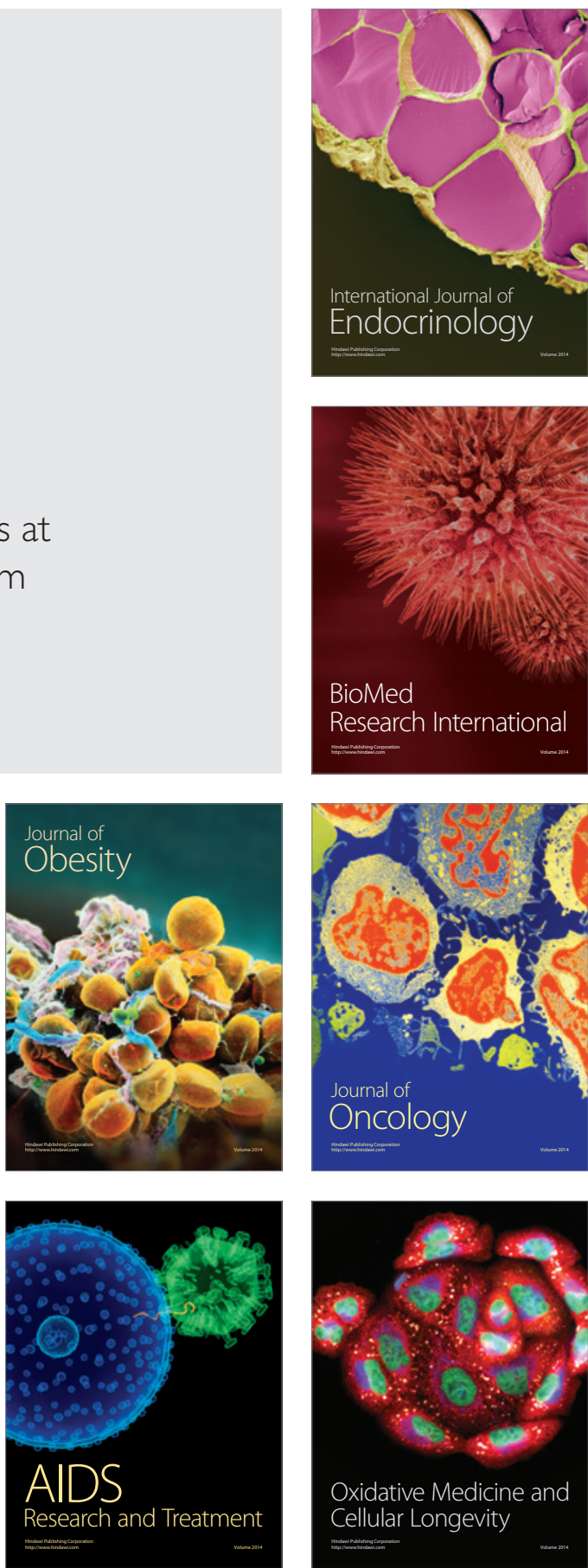